Pinner, M. (1938). Amer. Rev. Tuberc., 37, 690.

Pruvost, P., and Depierre (1946). Bull. Soc. méd. Hôp., Paris, 62, 341 .

Pulaski, E. J., and White, T. T. (1948). Arch. intern. Med., 82, 217.

Reisner, D. (1944). Amer. Rev. Tuberc., 49, $289,437$.

Ricker, W., and Clark, M. (1949). Amer. J. clin. Path., 19, 725.

Rubin, E. H., and Pinner, M. (1944). Amer. Rev. Tuberc., 49, 146.

Salyesen, H. A. (1935). Acta med. scand., 86, 127.

Scadding, J. G., and Sherlock, S. (1948). Thorax, 3, 79.

Schaumann, J. (1914). Sur le lupus pernio, publ. Stockholm, 1934. - (1933). Bull. Soc. franc. Derm. Syph., 40, 1167.

- (1936). Brit. J. Derm., 48, 399.

(1941). Acta med. scand. 106, 239

Schönholzer, G. (1947). Schweiz. med. Wschr., 77, 585

Skiöld, N. (1945). Acta med. scand., Suppl. is7.

Snapper, I., and Pompen, A. W. N.'(1938). Pseudo-tuberculosis in Man. Haarlem.

Spink, W. W., Hoffbauer, F. W., Walker, W. W., and Green, R. A. (1949). J. Lab. clin. Med., 34, 40.

- and Sundberg, R. D. (1947). Blood, Suppl. 1, p. 7.

Tice, F., and Sweany, H. C. (1941). Ann. intern. Med., 15, 597.

Ustvedt, H. J. (1948). Tubercle, 29, 107.

van Beek, C., and Haex, A. J. C. (1943a). Ned. Tijdschr. Geneesk. 87, 1264

(1943b). Acta med. scand., 113, 125.

(1948). Ned. Tijdschr. Geneєsk., 92,4171

van Buchem, F. S. P. (1946). Acta med. scand., 124, 168.

Vosbein, E. B., and Bonnevie, P. (1940). Acta derm.-venereol., Stockh., 21, 408.

\section{AMYLOIDOSIS IN RHEUMATOID ARTHRITIS}

BY

\section{G. H. JENNINGS, M.D., F.R.C.P.}

Senior Physician, Edgware General Hospital

\section{[With Photogravure Plate]}

The association of amyloid disease and rheumatoid arthritis was described first by Whitman (1903) in an account of two cases of Still's disease with enlarged liver and spleen: the one of these patients who died was proved to have gross amyloidosis in the liver, spleen, kidneys, and mesenteric glands. This patient, like all those since recorded with associated rheumatoid arthritis and amyloidosis, was emaciated. In 1906 Beattie described four cases in which patients between 19 and 28 years of age had had relapsing acute rheumatism for from seven months to four years. All four patients died, and amyloid disease was found in their liver, spleen, and kidneys. In the three in whom diarrhoea was noted amyloid changes were found in the villi of the small intestine.

No further case of rheumatoid arthritis and amyloidosis was described until 1927, when Carroll and Nelson reported a fatal examp'e in a boy with Still's disease. Since this case fewer than 50 cases have appeared in the literature. By 1944 Trasoff $e t$ al. had collected 14 cases of amyloidosis in Still's disease and 17 in adult rheumatoid arthritis. In 1947 Yeoman and Wilson referred to 30 adult cases of rheumatoid arthritis with amyloidosis. To this number can be added the two following cases.

\section{Case 1}

A female warehouse assistant aged 23 had an attack of tonsillitis during the summer of 1943 . This was followed by stiffness and swelling of the knees, ankles, wrists, and fingers. The swelling persisted with fluctuations up to the time of her admission to this hospital five years later. During that time, both in and out of hospital, she had received dental treatment, physiotherapy to the affected joints and neighbouring muscles, vitamin concentrates, iron, one course of auro-calcium, and two courses of sodium aurothiomalate ("myocrisin "). These courses consisted of weekly injections; the first (12 injections) totalled $0.6 \mathrm{~g}$., the second ( 20 injections) $1 \mathrm{~g}$., and the third (13 injections) $0.95 \mathrm{~g}$. Urine was normal throughout.

The affected joints settled with the first two courses, but chronic deformities were marked in the hands and wrists at the end of the second course. She rested two months, and the E.S.R. was then (June 24,1947$) 38 \mathrm{~mm}$. Slight exercise was allowed and improvement was maintained, though there was occasional pain in the joints, and on September 2, 1947, the E.S.R. was $24 \mathrm{~mm}$. During the third course of gold injections, which then followed, she had occasional attacks of petit mal, but remained fairly well until early March, 1948, and was able to walk, which she could not do from 1945 to 1947 . At the beginning of March both knees became painful, hot, and swollen, and she was again unable to walk. She also became generally ill, pale, and febrile (temperature $99.8^{\circ} \mathrm{F} .\left(37.7^{\circ} \mathrm{C}\right.$ ), pulse 110$)$. There was loss of weight, but no severe sweating. As the knee-joints did not settle she was admitted to Edgware General Hospital, and was kept under treatment (mostly in bed) for three months.

When admitted on May 5, 1948, she was thin, flushed but anaemic, with marked dental sepsis and gum infection. Severe bilateral chronic deformity of the hands and wrists was present, and neither elbow could be fully extended. There was moderate movement in the wrists, but finger flexion was much impaired. Both knees were swollen, warm, and painful; the left, which was more markedly affected, could not be fully extended. The liver was greatly enlarged and the spleen just palpable (Fig. A). Puncture biopsy (June 2) proved the liver enlargement to be due to amyloid.

With physiotherapy (including splinting) and the elimination of dental sepsis the knee swellings settled considerably, a nd both knees could not only be fully extended but also had a fair degree of flexion. By the time of her discharge she was able to walk with help, and the E.S.R. had by then fallen from 89 to $68 \mathrm{~mm}$. There was a low-grade fever (99$100^{\circ}$ F. $-37.2-37.8^{\circ} \mathrm{C}$.) during the first nine weeks, but this settled gradually to normal during the last four weeks in hospital. A course of systemic penicillin $\quad(500.000$ units daily) was given

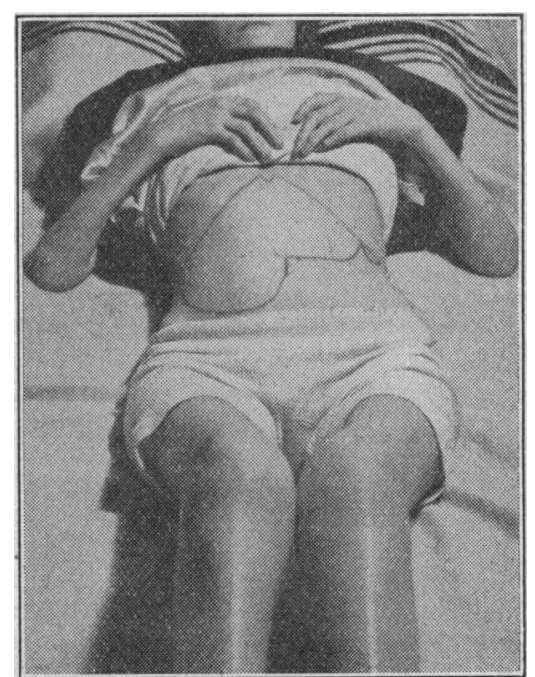

Fig. A.-Case 1 nıne months atter disment she still shows gross liver and slight splenic enlargement. Rheumatoid changes in knees, wrists, and fingers are present and muscular wasting is still evident. charge from ward. In spite of improve-

for three weeks, and

a Bact. coli urinary infection was eliminated with sulphonamides. She was also given iron (ferrous sulphate $18 \mathrm{gr}$. (1.2 g.) daily) and ascorbic acid. Her haemoglobin rose from $50 \%$ to $90 \%$ (Haldane) and the red blood cells from $4,120,000$ to $5,180,000$ during her stay in hospital. She was discharged on August 7, 1948.

Since her discharge she has had oral whole liver as well as iron and ascorbic acid, and physiotherapy has been continued. The enlargement of the liver and spleen has persisted unchanged to the time of writing (September 10, 1949). Her knee-joints, elbows, wrists, fingers, and ankles still show chronic rheumatoid deformity (Fig. A), but only the right hip is painful. It is also very stiff, as are the fingers, but all other joints have a satisfactory range of movement, so that she can progress a little on crutches. Her general condition is slightly improved and there is no oedema. Her blood pressure was $110 / 80$.

Investigations During Stay in Hospital--Radiographs on May 14, 1948, revealed chronic rheumatoid arthritis of long standing in hands and wrists, with moderate osteoporosis and destruction of articular surfaces. The knees showed an early stage of rheumatoid arthritis, with no bone destruction or rarefaction, but with diminished joint spaces. The teeth showed apical rarefaction and sepsis as well as cavitation in places. 
On May 5 the plasma proteins were : total, 7.5 g.\%; albumin, 3.6 g. \% ; globulin, 3.9 g.\% The serum alkaline phosphatase was 8.7 units (King and Armstrong). The thymol turbidity was negative. The blood W.R. was negative, and the blood-sugar curve on May 5 was within normal limits. On July 19 the urine showed : protein +++ , few white blood cells, and occasional granular and hyaline casts.

Investigations Since Discharge.-The plasma proteins on December 5, 1948, were : total, 7.5 g. \% ; albumin, $4.4 \mathrm{~g} . \%$; globulin, $3.1 \mathrm{~g} . \%$. On 'June 24, 1949, they were : total, $8 \mathrm{~g} . \%$; albumin, 3.8 g.\% ; globulin. 4.2 g.\%. At that date the urine showed : protein +++ , white blood cells, and a few hyaline casts ; and on September 2 : protein +++ and a few granular casts. The blood urea on June 24 was $27 \mathrm{mg}$. per $100 \mathrm{ml}$. A blood count on July 1 showed : red cells, 4,800,000 per c.mm.; $\mathrm{Hb}, 74 \%$ (Haldane); C.I., 0.77 ; white cells, 4,400 (normal differential). On October 11 it showed : red cells, 5,700,000 per c.mm.; Hb, 72\% (Haldane); C.I., 0.64; white cells, 4,600. The E.S.R. (Westergren) was $51 \mathrm{~mm}$. in the first hour on July 1, and $6 \mathrm{~mm}$. on September 2 . A radiograph of the hips on June 27, 1949, revealed an eburnating arthritis, more marked on the right side. The joint spaces were much diminished, but there was no bony ankylosis and the bone was of normal density. The hands and wrists were unchanged.

\section{Case 2}

A man aged 65 was admitted to Edgware General Hospital on April 16, 1949, shortly after having a large haematemesis with melaena. Previous history was of rheumatoid arthritis for about four years which had been treated at the Red Cross Clinic, Peto Place, for three years. His knees and feet were first involved, and on March 26, 1946, a radiograph of the left knee showed slight narrowing of the joint space, with periarticular thickening. He received a course of auro-calcium between May 29 and September 5, 1946, and then, when a total of $0.11 \mathrm{~g}$. had been given, a slight but persistent albuminuria caused the treatment to be stopped. Physiotherapy was continued, but he made no real improvement. On November 12 his wrists, fingers, and knees showed marked rheumatoid changes, and radiographs of these joints revealed the characteristic osteoporosis and loss of joint cartilage. His E.S.R. (Westergren) remained at about $80 \mathrm{~mm}$. throughout the latter half of 1946, but by April 10,1947, it had risen to $100 \mathrm{~mm}$. Routine blood counts throughout this period showed no abnormality, but by the end of 1948 his haemoglobin level was 49\% (Haldane).

On March 14, 1949, his general condition and joint condition were much worse. The knees were fixed in flexion, and the fingers, wrists, and elbows showed gross rheumatoid changes. Radiographs revealed erosion of the joint surfaces of the knees. His E.S.R. was still $100 \mathrm{~mm}$. and the red blood cells numbered 2,300.000, with $\mathrm{Hb} 40 \%$.

On admission after the haematemesis he appeared almost exsanguinated, and lay feeble and dazed. He was much wasted, and his knees were fixed in flexion. The other joints mentioned above showed gross rheumatoid changes. The heart was not obviously enlarged; there was a blowing apical S.M. The pulse rate was 130 , and the B.P. 85/35. The chest and abdomen were normal. The liver and spleen were not felt. The urine showed a heavy cloud of albumin.

He was immediately transfused with 2 pints (1.14 litres) of blood, and a further 2 pints was given four days later. The melaena gradually ceased and the haemoglobin rose to $62 \%$.

Four weeks later (May 24) the patient's condition again began to deteriorate; his throat became sore and his breathing laboured; he complained of retrosternal discomfort, and was unable to sleep. The tongue was dry and smooth; small red vesicles appeared in the sacral area. The haemoglobin was now $54 \%$.

On the 25th he was much worse-drowsy and breathing deeply and rapidly (28). His pulse was 80 and B.P. 108/55. There were petechiae in the throat, and the spleen was just palpable. The urine now contained more than $1 \%$ of protein with a few red blood cells, but no casts. The blood urea was over
$500 \mathrm{mg}$. per $100 \mathrm{ml}$. The patient died in uraemic coma that evening.

Post-mortem Examination (Dr. J. L. Hamilton-Paterson).A moderately nourished man. Marked contraction of knees and hips as a result of old rheumatoid arthritis. Rheumatoid deformities also of hands and fingers. Heart : No abnormality apart from an old adhesive pericarditis. Lungs : Early right lower lobe bronchopneumonia. Liver enlarged and showing obvious diffuse amyloidosis on section. Spleen average size no macroscopic amyloid. Kidneys enlarged and adherent to perirenal tissues; cortex grossly narrowed and pale; medulla apparently normal : changes very suggestive of nephrosclerosis following amyloid disease. Alimentary canal : Stomach and duodenum normal ; small intestine showed patchy distribution of oedema and submucous petechial haemorrhages; large intestine contained tarry blood; gross congestion and oedema of mucous membrane at irregular intervals, but no ulceration appearances those of uraemic inflammation. All other organs were normal.

Microscopy showed diffuse amyloidosis of the liver (Plate. Fig. 2), glomerular and tubular amyloid degeneration of the kidneys (Fig. 3), and slight amyloid degeneration of the spleen (Fig. 1). The heart showed fibrinous pericarditis, and some cellular infiltration of the myocardium with histiocytes and eosinophils.

The amyloidosis of rheumatoid arthritis is of the second. ary type involving the kidneys most frequently, next the liver and spleen, and less often the suprarenals, lymph nodes, and intestines. The kidneys, and more rarely the spleen, may be involved alone. Hadfield (quoted by Hill. 1948) has described amyloid as "a structureless glyco. protein found in the tissues as an insoluble gel, and first appearing between the scanty cells of the endothelial lining of the capillary blood vessels." It lies outside the cells, greatly thickens the blood-vessel walls, and steadily progresses to cause great enlargement and translucency of the affected organs.

Its mode of development has provoked much discussion, and some authors-for example, Reimann and Eklund (1935)-bearing in mind its association with chronic infections, malignancy, and multiple myelomatosis, diseases in which the blood-protein levels are disturbed, would attribute it to an increase in the normal or abnormal blood globulins. If rabbits are injected with casein amyloidosis develops after the blood globulins have been doubled or quadrupled. But renal amyloidosis can also be produced in rabbits by injecting such varied substances as bacterial toxins (Boyd, 1947) and subcutaneous manganese chloride (Butt, 1930).

Reimann and Eklund support their view by quoting the observations of Langstein and Mayer (1903), who found that animals treated with vaccines developed amyloidosis. They feel that humap beings receiving vaccine therapy may develop excess amounts of normal globulins or new abnormal proteins, and that these may be deposited in the tissues and converted into amyloid. But it must be emphasized that while cases with raised blood globulins and amyloid disease, like Case 1 , are not infrequent, review of other described cases of secondary amyloidosis shows no constant relation between the development of amyloid and the level of the blood globulins (Trasoff et al., 1944: Rosenblatt, 1933). A relative globulin increase is of course a secondary finding where renal amyloidosis has led to heavy albuminuria. Many cases of amyloidosis have had neither vaccine therapy nor chrysotherapy, the latter being implicated by Doubrow (quoted by Reimann and Eklund, 1935 ) as a possible cause of amyloidosis.

The described cases of rheumatoid disease have always been sêvere examples of the condition, usually much 
emaciated and often anaemic as well, before they deve'oped recognizable amyloidosis. The disease has also nearly always been protracted before the amyloidosis became apparent, though in a recent case the latter condition was recognized only eight months after the onset of the arthritis (Lush, Chalmers, and Fletcher, 1948). This combination of length and severity of the primary disease suggests that in rheumatoid and rheumatic disease, as in tuberculosis or suppuration, the toxins of the infection cause the amyloidosis. Eagles and his co-workers (1937) stated that the same virus causes both acute rheumatism and rheumatoid arthritis ; and Mervyn Gordon (1948), in supporting this view, has pointed out that the fibrinoid degeneration of acute rheumatism may progress to amyloid degeneration. Beattie's cases of rheumatism, mentioned early in this paper, also seem to support this statement-as does the case of Imrie and Aitkenhead (1939) in which rheumatic fever led, after several years, to Still's disease and fatal amyloidosis.

Goldthwait (1940) has reported amyloidosis in $21 \%$ of the cases of rheumatoid arthritis which he has examined at necropsy, while Lush et al. found only one case among 200 rheumatoid arthritics examined in a clinic. The discrepancy between these two findings is accounted for both by the difficulty of recognizing amyloid disease in life and by its greater incidence in protracted and terminal cases; but the true rate of incidence evidently lies nearer to Lush's figure than to Goldthwait's, because of the many. mild or moderate cases of rheumatoid arthritis which recover and in which there is no likelihood of amyloidosis.

\section{Pathology}

Secondary amyloidosis, with which this paper is concerned, differs from the primary amyloid disease sometimes seen in the tongue, alimentary tract, heart, and pericardium, in which no preceding cause is to be found, and in which not only the distribution of the amyloid substance, but also its composition, is different from that seen in secondary amyloidosis (Reimann et al., 1935 ; Baber, 1947 ; Findley and Adams, 1948). But the exact composition and mode of formation of the amyloid is not fully known in either type. It is probably formed locally from connective-tissue elements (Warren, 1930), and I am indebted to my colleague, Dr. J. L. Hamilton-Paterson, for the observation that it probably represents a pathological change in the connective-tissue ground substance.

In the secondary type of disease deposition occurs generally in connective tissue and especially betueen and beneath the endothelial lining cells of the capillaries-for example, in the renal glomeruli (Fig. 3). The glomerular changes are responsible for albuminuria and, if extensive enough, for the one fatal result of amyloidosis, uraemia (Rosenblatt, 1933). Rosenblatt thinks with Fahr that in this disease the tubular degeneration is a proportional result of the glomerular damage. The cells are first swollen and contain fatty droplets (" amyloid nephrosis") ; later there is marked atrophy. The only direct involvement of the tubules by amyloid is a slight and scattered deposition on the basement membranes (see Fig. 3).

Rosenblatt, whose cases were mostly victims of tuberculosis, found that out of 125 there were $87(70 \%)$ showing renal involvement. Of these, $34 \%$ showed amyloid nephrosis and had a corresponding history of marked albuminuria and oedema. By contrast it is interesting to note that our second case showed renal contraction and marked uraemia and gave no history of an oedematous phase in his illness.

In Rosenblatt's series the spleen was involved most frequently-in 108 instances $(88 \%)$; the liver was involved in $76(60 \%)$; and the adrenals in $50(40 \%)$. In no other organ or tissue was there any incidence in any way comparable to that found in these four sites.

When the spleen is involved it shows, as did Case 2, an involvement of the walls of the arterioles of the Malpighian bodies (Fig. 1). In this case the spleen was only lightly affected, but the liver changes were heavy (Fig. 2); and here again the deposits were in the characteristic placein the connective tissue between the sinus endothelium and the liver cells, the latter being compressed by the larger deposits.

A sufficient number of cases of amyloidosis in rheumatoid arthritis have been described during the past 20 years to suggest that this complication of rheumatic and rheumatoid disease will be recognized more often if it is always suspected when the condition has lasted over a year and has been severe enough to have led to marked loss of weight and to anaemia. Since the kidneys are most frequently and most seriously involved, albuminuria with hyaline and granular casts may be the best pointer. Hill (1948) has suggested that a " nephrotic syndrome" is a likely development, and claims that both nitrogen retention and hypertension very rarely develop in rheumatoid renal amyloid disease. Trasoff et al., however, report that nine out of their 13 cases showed terminal uraemia. The rarity of hypertension in renal amyloidosis (Rosenblatt) and Hill's emphasis on the frequent, if often delayed, appearance of oedema in this condition are noteworthy. Oedema does not always occur in renal amyloidosis (for example, Case 2), though it is frequent and always to be expected when the serum albumin and total protein levels have been much lowered by albuminuria. The liver and spleen are also often involved by amyloid changes, and so hepatomegaly or splenomegaly, alone or associated, may be evidence of the disease. Case 1 suggests that liver biopsy is a safe, easy, and reliable diagnostic test when a large firm liver appearing in rheumatoid arthritis has suggested amyloid disease. Very occasionally, as in the case of Lush et al., biopsy examination of enlarged lymph nodes occurring in rheumatoid arthritis may first show the amyloid disease.

The injection of Congo red, or the Paunz test, though not without risk, gives useful though variable information (Trasoff et al.). The test may show $90 \%$ retention of the dye in the first hour, but it is known that, exceptionally, cases of amyloid disease have shown as low a figure as $40 \%$. A retention level of $65 \%$ is very suggestive of secondary amyloidosis. In primary amyloidosis where the "inmature" amyloid does not absorb the dye (Reimann et al.) the test has no value.

Prognosis is most grave when nitrogen retention occurs ; marked oedema, whilst a serious matter, is not of itself fatal. Gross hepatomegaly and splenomegaly due to amyloidosis have of themselves no direct influence on the eventual course and outcome of the primary disease.

\section{Treatment}

First treatment of secondary amyloid disease is to eliminate the causative complaint. An empirical form of therapy with oral whole liver extract has also been tried in recent years.

The effective nature of the first line of treatment was well shown in an adult with a tuberculous empyema complicated by severe renal, splenic, and hepatic amyloidosis. In the three years following effective drainage of the empyema the amyloidosis appeared to clear entirely (Rosenblatt, 1936): In a similar period Walker (1928) observed complete regression of gross amyloidosis of liver 
and spleen in a small boy after his chronic post-pneumonic empyema had been closed by thoracoplasty. Sherlock (1945), by liver biopsy in a case of chronic diarrhoea due to an unexplained ileo-sigmoid fistula, found that after two years her patient had gained weight despite continued moderate diarrhoea, and that his amyloid infiltration was considerably "less coarse."

Liver therapy cannot be said to have benefited any of these cases, though it was given during convalescence by Rosenblatt, but in the cases of Trasoff et al. (1944) and of Kennedy (1935) it may have had some good effect.

\section{Summary and Conclusions}

Two cases of rheumatoid arthritis complicated by amyloid disease have been described. Although there is uncertainty about the mode of production of this disease, it is noteworthy that in both cases the rheumatoid condition had been protracted and had caused pronounced wasting and anaemia as well as crippling joint changes.

In one case the disease had brought about blood-protein changes, only partly attributable to the severe associated albuminuria.

It is suggested that the amyloid-tissue changes are not due to the blood-protein changes, but that both are attributable to the rheumatoid infection.

Each case had had moderate gold therapy, but this probably had no bearing on the development of amyloidosis.

It is noted that one case, in spite of gross hepatic enlargement, splenomegaly, and marked albuminuria, shows no deterioration. The other patient died in uraemia, the only way in which amyloid disease can directly cause death.

Where the liver is enlarged, liver biopsy may be used with safety to establish the diagnosis.

Treatment with whole liver extract has so far had no definite effect on the amyloid deposits.

It is suggested that secondary amyloidosis is dispersed only after cure of the primary complaint.

It will be interesting to observe the effect of cortisone on the amyloid changes due to rheumatoid arthritis.

I am indebted to Dr. K. M. Lawther, of Middlesex Hospital, for details of the early course of the illness in Case 2, and to my colleague, Dr. L. I. M. Castleden, for the later notes on the same case. I am grateful to Dr. J. L. Hamilton-Paterson for help with the investigations and histology in these two cases, to Miss $\mathbf{M}$. $\mathbf{H}$. Shaw for the preparation of the photomicrographs and the photograph of Case 1, and to Dr. G. M. Barrett for the liver biopsy specimen from the same case.

\section{REFERENCES}

Baber, M. D. (1947). Lancet, 1, 210

Beattie, J. M. (1906). British Medical Journal, 2, 1444.

Boyd, W. (1947). Textbook of Pathology, 5th ed.,. p. 29. London Butt, E. M. (1930). Arch. Path., 10, 859.

Carroll, J. H., and Nelson, R. L. (1927). Arch. Pediat., 44, 187.

Eagles, G. H., Evans, P. R., Fisher, A. G. T., and Keith, J. D. (1937). Lancet, $2,421$.

Findley, J. W., and Adams, W. (1948). Arch. intern. Med., 81, 342. Goldthwait, J. E. (1940). New Engl. J. Med., 223, 568.

Gordon, M. H. (1948). Lancet, 1, 697.

Hill, L. C. (1948). Proc. R. Soc. Med., 41, 607.

Imrie, A. H., and Aitkenhead, A. C. (1939). Lancet, 2, 421.

Kennedy, W.' R. (1935). Canad. med. Ass. J., 33, 385 .

Langstein, L., and Mayer, M. (1903). Beitr. chem. Physiol. Path. 5, 69.

Lush, B., Chalmers, I. S., and Fletcher, E. (1948). Ann. rheum. Dis., 7, 225.

Reimann, H. A., and Eklund, C. M. (1935). Amer. J. med. Sci. $190,88$.

Koucky, R. F., and Eklund, C. M. (1935). Amer. J. Path., 11 977.

Rosenblatt, M. B. (1933). Amer. J. med. Sci., 186, 558.

(1936). Arch. intern Med., 57, 562.

Sherlock, S. (1945). Lancet, 2, 397.

Trasoff, A., Schneeberg, N., and Scarf, M. (1944). Arch. intern. Med., 74, 4.

Walker, G. F. (1928). Lancet, 2, 120

Warren, S. (1930). Amer. J. Path., 6, 161.

Whitman, R. (1903). Med. Rec., 63, 601.

Yeoman, W., and Wilson, J. V. (1947). British Medical Journal, 2, 483 .

\section{MEDICAL ADMINISTRATION IN THE TROPICS}

\author{
BY
}

GeORGe MACleAN, C.B.E., M.B., Ch.B.

Formerly Deputy Director of Medical Services in Tanganyika Territory, and Director of Medical Services, Trinidad and Tobago

Medical administration in the Tropics presents certain special features of its own. The climate, the prevalence of debilitating and often fatal communicable diseases, the effects on health and social life generally of economic development on the one hand or economic stagnation on the other, and, in many instances, the customs and beliefs of the general population in regard to diseases and their causation, all combine to produce conditions which differ in many important respects from those met in the more organized countries of temperate climates.

The situation in Tanganyika Territory after the 1914-18 war serves to illustrate the problems which face a medical service dealing with primitive conditions, while that in Trinidad and Tobago, with well-organized industries and more than a century of medical services, provides examples of the problems met in a comparatively advanced country.

\section{Health Conditions and Medical Services in Tanganyika Territory}

When the British took over the administration of German East Africa, as Tanganyika Territory was then, the effects of war were so devastating that, though some hospitals and laboratories were available and a number of trained dressers still remained, such medical services as the German Government had developed had almost completely disintegrated. The war was followed by a pandemic of influenza and by extensive famines.

As the British civil administration replaced the military occupation a medical department was gradually built up. But even in 1921 a medical officer, assisted by a few sub. assistant surgeons, compounders, and dressers, might find himself responsible for the public health of a quarter of a million people, or even (though rarely) half a million. Such a service could touch only a fraction of the population, and indigenous forms of medicine and public health were widely practised. How effective the herbal remedies were it was hard to assess. It was rarely possible for an outside observer to study individual patients who were under treatment, and even more difficult to get to knou the remedy used, as the "trade secrets" were closely guarded. For example, claims of success were made in the treatment of gonococcal infections, and there were apparently some grounds for the claims.

The abandonment of a house after one or more deaths had taken place in it seems to have been a common practice, and there may have been occasions when the custom was of benefit as a public health measure. The circumstances in which I saw the abandonment of houses most in evidence were during a sleeping-sickness epidemic, and the consequences were the opposite of salutary in that the effect was to spread the disease over thousands of square miles. Variolation was another common practice, and it is not improbable that it contributed to the dissemination of infection.

Witchcraft played its part in the sphere of health. It was, for example, apparently believed over a wide area 
J. G. SCADDING: SARCOIDOSIS, WITH SPECIAL REFERENCE TO LUNG CHANGES
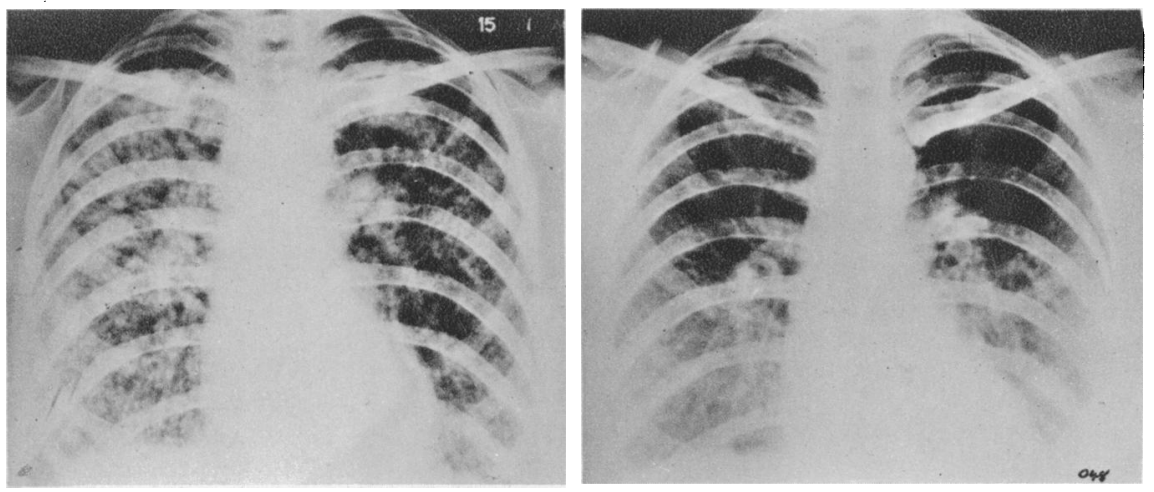

FIG. 8.-Case 11. Radiograph of chest; Fig. 9.-Case 11. Radiograph of chest; January, 1948.

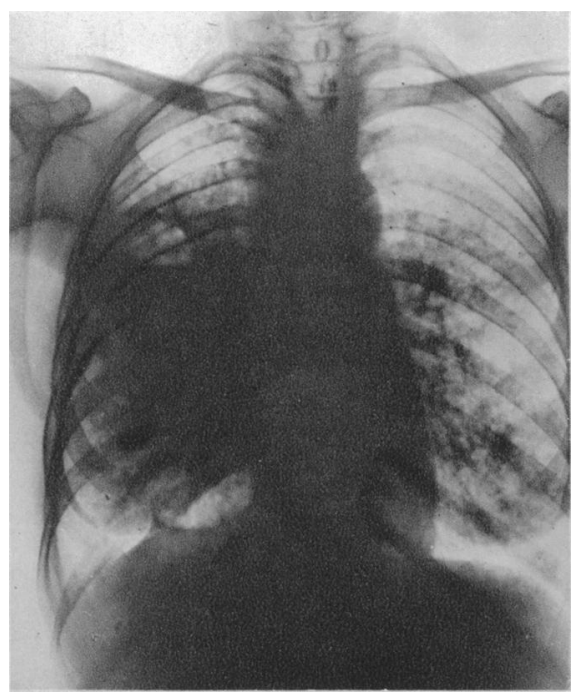

Fig. 10.-Case 16. Radiograph of chest; Fig. 11.-Case 16. Radiograph of chest: June, 1949.
H. C. MCLAREN: CANCER OF UTERUS IN ADRENOGENITALISM

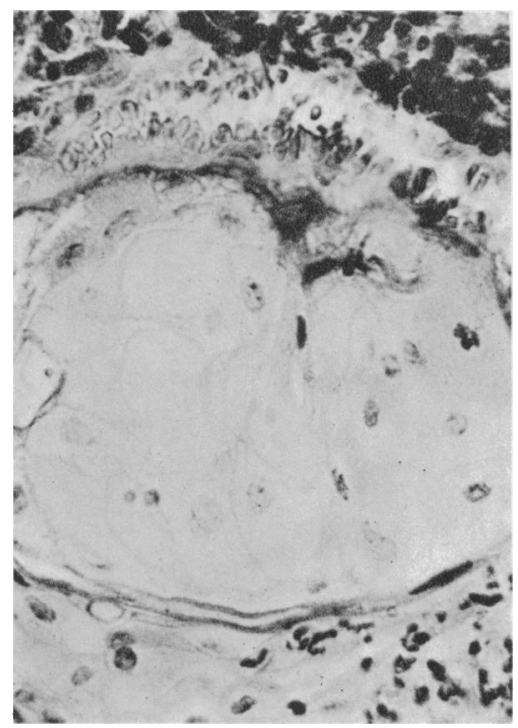

FIG. 1.-Adeno-acanthoma with circumscribed pale area. $(\times 480$.

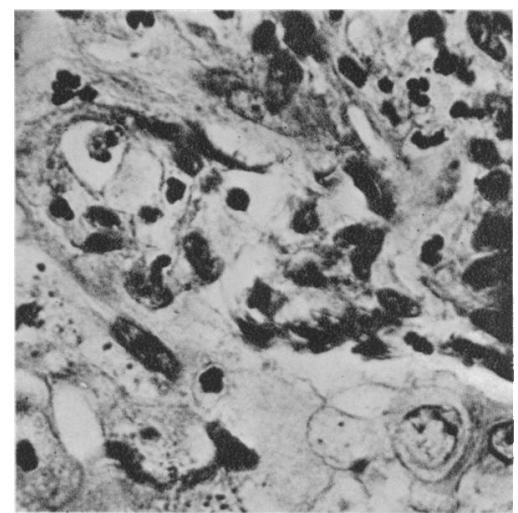

Fig. 2.-Metaplasia. Cytoplasm of irregularly shaped epithelial cells is pale staining with hæmatoxylin-eosin; some of the nuclei are fragmented. $(\therefore 480$.

\section{G. H. JENNINGS: AMYLOIDOSIS IN RHEUMATOID ARTHRITIS}

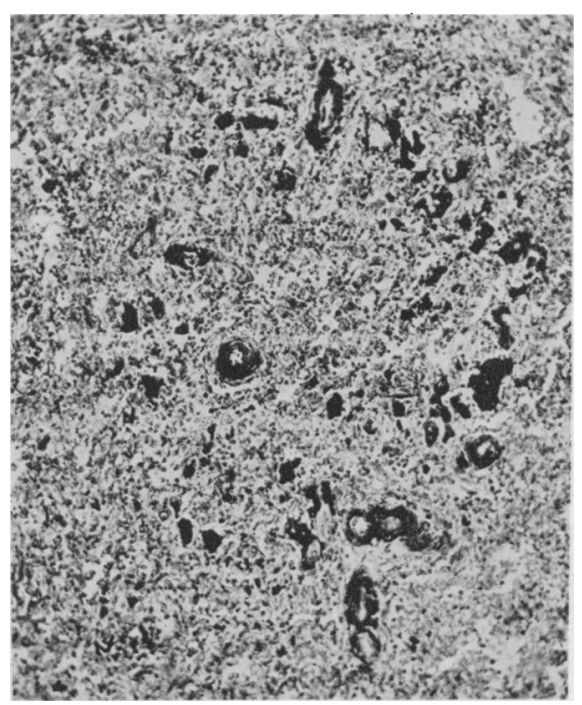

Fig. 1.-Case 2. Spleen $(\times 85)$. Methyl violet stain shows amyloid in central arteriole of Malpighian corpuscle and in smaller arteriolar branches around periphery.

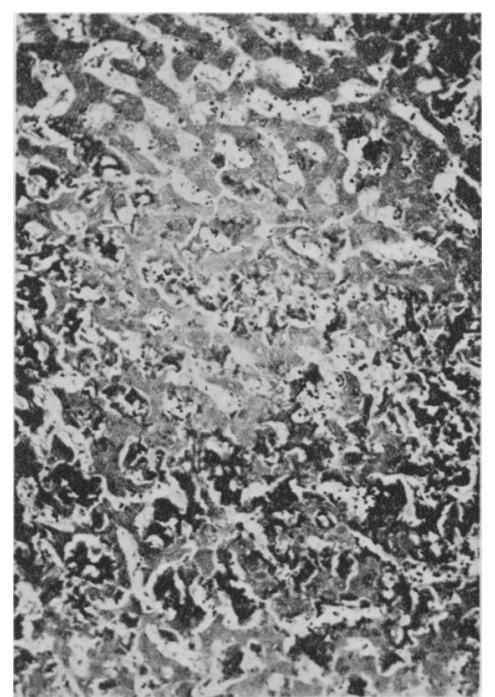

FIG. 2.-Case 2. Liver (, 85). Dark-staining amyloid material between sinus endothelium and compressed, degenerated liver cells.

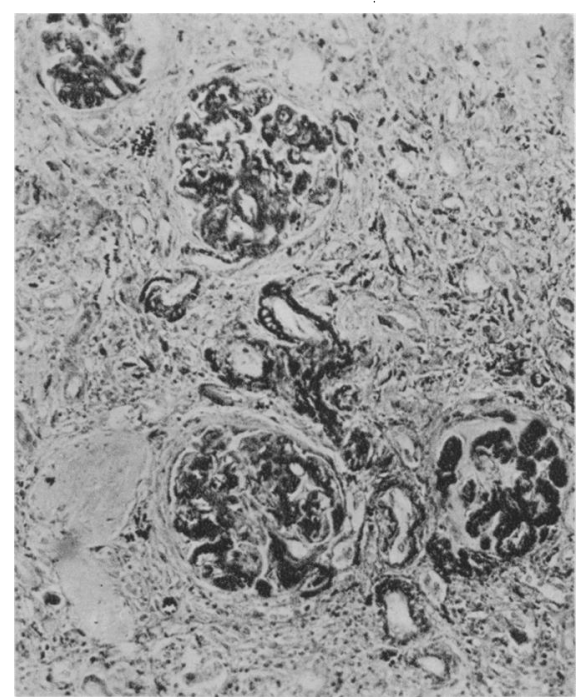

Fig. 3.-Case 2. Kidney $(\times 85)$. Amyloid changes in glomeruli and afferent arterioles: tubular degeneration; replacement fibrosis. 